\title{
BMJ Open The 2015 Middle Childhood Survey (MCS) of mental health and well-being at age 11 years in an Australian population cohort
}

Kristin R Laurens, ${ }^{1,2,3}$ Stacy Tzoumakis, ${ }^{4}$ Kimberlie Dean, ${ }^{1,2,5}$ Sally A Brinkman, ${ }^{6,7}$ Miles Bore, ${ }^{8}$ Rhoshel K Lenroot, ${ }^{1,2}$ Maxwell Smith, ${ }^{9}$ Allyson Holbrook, ${ }^{9}$ Kim M Robinson, ${ }^{9}$ Robert Stevens, ${ }^{10}$ Felicity Harris, ${ }^{1,2}$ Vaughan J Carr, ${ }^{1,2,11}$ Melissa J Green ${ }^{1,2}$

To cite: Laurens KR, Tzoumakis S, Dean K, et al. The 2015 Middle Childhood Survey (MCS) of mental health and well-being at age 11 years in an Australian population cohort. BMJ Open 2017;7:e016244. doi:10.1136/ bmjopen-2017-016244

- Prepublication history and additional material is available. To view, please visit the journal online (http://dx.doi.org/10. 1136/bmjopen-2017-016244)

Received 2 February 2017 Revised 29 March 2017 Accepted 30 March 2017

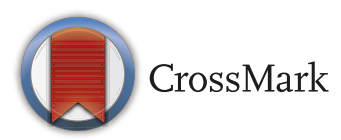

For numbered affiliations see end of article.

Correspondence to Dr Kristin R Laurens; kristin. laurens@unsw.edu.au

\section{ABSTRACT}

Purpose The Middle Childhood Survey (MCS) was designed as a computerised self-report assessment of children's mental health and well-being at approximately 11 years of age, conducted with a population cohort of 87 026 children being studied longitudinally within the New South Wales (NSW) Child Development Study.

Participants School Principals provided written consent for teachers to administer the MCS in class to year 6 students at 829 NSW schools (35.0\% of eligible schools). Parent or child opt-outs from participation were received for $4.3 \%$ of children, and MCS data obtained from 27808 children (mean age 11.5 years, SD $0.5 ; 49.5 \%$ female), representing $85.9 \%$ of students at participating schools. Findings to date Demographic characteristics of participating schools and children are representative of the NSW population. Children completed items measuring Social Integration, Prosocial Behaviour, Peer Relationship Problems, Supportive Relationships (at Home, School and in the Community), Empathy, Emotional Symptoms, Conduct Problems, Aggression, Attention, Inhibitory Control, Hyperactivity-Inattention, Total Difficulties (internalising and externalising psychopathology), Perceptual Sensitivity, Psychotic-Like Experiences, Personality, Selfesteem, Daytime Sleepiness and Connection to Nature. Distributions of responses on each item and construct demarcate competencies and vulnerabilities within the population: most children report mental health and wellbeing, but the population distribution spanned the full range of possible scores on every construct.

Future plans Multiagency, intergenerational linkage of the MCS data with health, education, child protection, justice and early childhood development records took place late in 2016. Linked data were used to elucidate patterns of risk and protection across early and middle child development, and these data will provide a foundation for future record linkages in the cohort that will track mental and physical health, social and educational/occupational outcomes into adolescence and early adulthood.

\section{INTRODUCTION}

Middle childhood (age 6-12 years) is a critical period in which to establish social,
Strengths and limitations of this study

- The Middle Childhood Survey (MCS) assessed psychosocial and behavioural constructs reflecting mental health and well-being by self-report in a large sample of 27808 children aged approximately 11 years (31.4\% of eligible children), which is representative of the New South Wales population.

- Constructs were assessed using items selected from measures with established reliability and validity for assessment of children aged 11 years, but item reduction and modifications made to item wording, response options and scale scoring limits direct comparison with published data on some measures.

- The depth of information obtained was constrained by the time available within schools for survey administration, lack of accompanying parent and/ or teacher reports and sensitivities associated with assessing psychosocial and behavioural constructs in children by self-report.

- The MCS measured the full spectrum of personal competencies and vulnerabilities in the population, providing capacity to guide the development and implementation of universal mental health promotion programmes alongside targeted approaches for vulnerable children.

- The MCS is embedded within an intergenerational, multiagency record linkage study, the New South Wales Child Development Study, which permits MCS data to be interpreted in the context of longitudinal data that is subject to minimal selection and participation bias.

emotional-behavioural, cognitive and physical competencies that support successful transition to adolescence. ${ }^{1}{ }^{2}$ Children are increasingly exposed to influences beyond the home, and encounter various new challenges, particularly at school. During this time, mental health problems emerge for some children, causing impairments in functioning and increasing risk for future 
adverse health, social and educational outcomes. ${ }^{34}$ Thus, middle childhood represents an important period for establishing strong psychosocial foundations to support future mental health and well-being. Here, we introduce the 2015 Middle Childhood Survey (MCS), designed as a self-report measure of children's psychosocial experiences in middle childhood (at approximately 11 years of age) administered online during the final year of primary (elementary) school for a population cohort of children being studied longitudinally within the New South Wales Child Development Study ${ }^{5}$ (NSW-CDS; http://nsw-cds. com.au/).

The NSW-CDS is a multigenerational record linkage study that combines administrative health, education, child protection and justice records for an Australian state-based population cohort of children $(n=87026)$ and their parents. The cohort was defined as those children who entered their first year of full-time schooling (Kindergarten) in NSW in 2009 at approximately 5 years of age and for whom class teachers completed the Australian Early Development Census ${ }^{6}$ (AEDC) on each child (99.7\% coverage). The AEDC data on early childhood social, emotional-behavioural, cognitive, communication and physical development were linked with child and parent administrative records in a first record linkage conducted in $2013^{5}$; a second record linkage that included MCS data and updated administrative records to the age of 12 years was undertaken in late 2016.

Reflecting the primary interest of the NSW-CDS in identifying childhood predictors of later mental health and related outcomes, ${ }^{5}$ the MCS items focused on the assessment of social and emotional-behavioural competencies that are typically attained during middle childhood $^{12}$ and which have been demonstrated as predictive of various adolescent and adulthood health and social outcomes. ${ }^{3} 77$ These competencies include establishing and maintaining positive social relationships, understanding and appreciating the perspectives of others, recognising and managing emotions and behaviours and the development of personality and self-esteem. Other aspects of childhood mental health and well-being that are associated with health, social and educational outcomes, such as psychotic-like experiences, ${ }^{78}$ daytime sleepiness ${ }^{9}$ and engagement with the natural environment ${ }^{10}$ were also included. Like the AEDC, the MCS was designed as a population measurement tool rather than a diagnostic instrument for the identification of children presenting needs that require specialist support services or therapeutic intervention. ${ }^{11}$ Thus, the MCS measured both successful attainment of these competencies as well as vulnerabilities or immaturity of these skills relative to age peers. This paper describes the content and administration of the MCS, and presents the mental health and well-being profiles of children in the MCS sample.
COHORT DESCRIPTION

\section{Eligible sample}

The target sample for the study included all year 6 students enrolled at government (public) and non-government (private) schools in the Australian state of New South Wales (NSW) during 2015 (88 572 children enrolled in 2371 schools), in order to capture the same cohort of children assessed within the AEDC in 2009. A two-stage recruitment procedure was used (figure 1) to ensure that students remained anonymous to researchers for future record linkage purposes: Principals (Head Teachers) provided active consent for their school to participate; subsequent child recruitment within participating schools was managed by school personnel using an opt-out consent procedure for parents and/or children.

\section{Procedures}

Pilot testing

Commencing in October 2012, school sector representatives and stakeholders representing various education and parent and communities groups (see Acknowledgements) were consulted regarding the method of MCS administration in schools. During 2014, the feasibility of administration procedures (and acceptability of the MCS items) was tested with year 6 students $(n=645)$ enrolled at 11 schools spanning the government and non-government sectors, and metropolitan and rural regions of NSW. Minor adaptations to administration procedures and MCS items were made on the basis of feedback received from participating schools, and on psychometric analysis of the pilot data (including factor and item response theory analyses).

\section{Data management}

The MCS data collection was managed by a third party information technology (IT) contractor that delivered the online student survey and the automated email correspondence with schools on behalf of the researchers. The IT contractor was provided with all Principal/school email addresses by the school sector representatives, and received all NSW year 6 students' identifying information (eg, name, date of birth), based on 2014 (year 5) enrolment records, directly from the NSW Board of Studies, Teaching and Educational Standards, under a confidential data usage agreement. Identifying information for these eligible students was prepopulated into an online administration portal that was accessible only to school teachers assisting with MCS administration. To account for new enrolments in 2015, teachers were able to update the personal identifiers to include new students. A unique access code was generated by the IT contractor for each child to ensure that the survey responses were associated with the correct personal identifiers for later linkage processes.

\section{School recruitment}

From March 2015, the school sector representatives and study stakeholders used their established avenues for communicating with school personnel and/or parents 


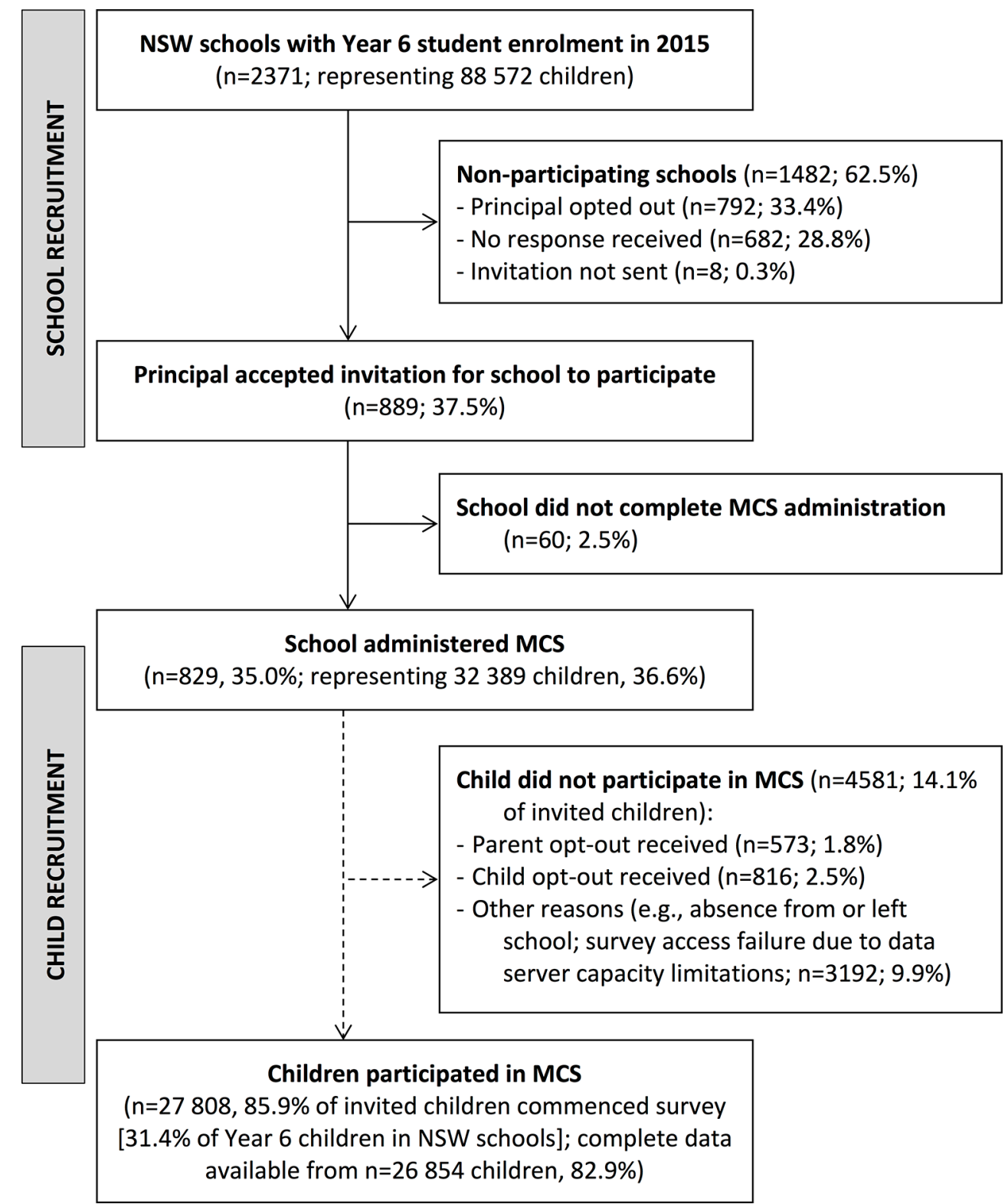

Figure 1 Flow diagram illustrating derivation of the final sample of 829 schools, and 27808 children, who participated in the Middle Childhood Survey 2015 (MCS). [NSW, New South Wales.]

to seek their support and participation in the study. In April 2015, Principals of NSW schools with an enrolment of year 6 students were sent an electronic study information leaflet by email, inviting the school to participate in the study. Principals (or an authorised representative) provided written informed consent for their school to participate, or declined participation, using a unique web-link for each school. Where no responses were received from schools during a 4-month school recruitment period, telephone contact was made by researchers and supplemented by automated reminder emails. Principals of participating schools were able to nominate a preferred 2-week window during July-September 2015 to administer the MCS, and a dedicated coordinator (ie, teacher or support person) to supervise MCS administration at their school.

\section{Child recruitment}

Both printed and electronic copies of study information leaflets were sent to participating schools for distribution to parents/carers of year 6 students at least a fortnight prior to the scheduled MCS administration. Electronic copies of these leaflets were also available on the study website in English and the 10 most common languages spoken by families of children enrolled in NSW schools; an audio version in English was also available at this site. Parents/carers could opt-out their child from participation using online forms, or by written or verbal instruction to class teachers. Children could opt-out either online or by verbal instruction to class teachers. Teachers recorded online any written or verbal opt-outs received from parents or children prior to administration of the MCS. Opting out of the study was also possible 
after MCS administration; capacity to withdraw MCS data remained available until the closure of the survey portal to data collection on 16 October 2015. MCS data were then deidentified by the IT contractor for provision to the researchers, at which point removal of a specific child's responses was no longer possible.

\section{Survey administration}

The MCS was administered within participating schools during class time over a 3-month period commencing July 2015. Classroom teachers supervised the survey administration according to instructions provided in an online administration guide. Schools determined the setting of survey administration depending on availability of computing resources, while maintaining confidentiality for participants. Children could complete the survey over multiple sessions, using the unique access code provided to the child by their teacher. Children with special needs could complete the survey with the assistance of their normal classroom support (eg, adult helper) and/or an audio-recording of the survey. Researchers monitored the administration of MCS in schools via an online portal (which held school-level information only), and arranged alternative administration times for any school that had not administered the survey within their nominated 2-week window.

\section{Data provision}

During the administration process, participating students' personal identifiers were stored by the IT contractor separately from MCS responses. Only deidentified survey data (coded by unique identification number) was provided to the researchers in December 2015. A separate dataset containing only the minimum identifying information for the cohort of participating students (ie, without the survey response data) was provided to a third party linkage provider-the Centre for Health and Record Linkage (http://www.cherel.org.au/) - to be retained under a confidential data usage agreement that enables linkage of MCS data with administrative data collections in the NSW-CDS; at no time during the study execution were personal identifiers available to researchers.

\section{Measures}

The content of the MCS was established via consensus among a working group comprising NSW-CDS Scientific Committee members who are coauthors on this manuscript. Members represented expertise in child development, developmental psychopathology, education, psychology, psychiatry and population health. The group reviewed measures with established reliability and validity for assessment of children aged 11 years, and incorporated measures both of competencies and vulnerabilities in social and emotional-behavioural development. Each construct of interest was assessed by multiple items; in some instances, only a subset of the items from the original scales was included due to constraints on the number of items that could be administered to children during class time. In such cases, the subset of items demonstrated in previous studies as providing the most coherent but comprehensive assessment of the construct was selected. Minor wording changes were made to several MCS items to increase their acceptability to Australian children (modified items are indicated by * in table 1 and online supplementary table 1-X). Furthermore, to avoid children having to adapt their responses to the different response formats used in the original scales, a standardised response format was adopted for all items, modelled on the three-choice format of the Strengths and Difficulties Questionnaire (SDQ), ${ }^{12}{ }^{13}$ namely: not true (scored 0); somewhat true (1) and certainly true (2). A standard approach of summing items on all scales (after reverse scoring of some items, as indicated in table 1 and online supplementary table $1-\mathrm{X}$ ) to compute total scale scores was also adopted.

In total, the MCS comprised 116 items with specific forced-choice response options. The first eight items assessed demographic information: age, sex, month of birth, residential postcode, number of people living in the child's usual residence, main language spoken at home and whether the child used the audio-recording or received assistance from an adult to complete the survey (table 2). The remaining 108 items assessed a range of child mental health and well-being constructs, including: Social Integration, Prosocial Behaviour, Peer Relationship Problems, Supportive Relationships (at home, school and in the community), Empathy, Emotional Symptoms, Conduct Problems, Aggression, Attention, Inhibitory Control, Hyperactivity-Inattention, Total Difficulties (internalising and externalising psychopathology), Perceptual Sensitivity, Psychotic-Like Experiences, Personality, Self-esteem, Daytime Sleepiness and Connection to Nature (engagement with natural environment). The source measure for each of these constructs is described below; for brevity, these are presented according to their questionnaire of derivation:

a. Social Integration at school was assessed using the full, unmodified 8-item Social Integration subscale of the Quality of School Life questionnaire. ${ }^{14}$ Response options were reduced from the original 4-choice to the standard 3-choice response format, and the total sum of items derived in place of an average of items used in previous research.

b. Prosocial Behaviour and Psychopathology were assessed using the 25-item SDQ ${ }^{12} 13$ which comprises four psychopathology subscales (Emotional Symptoms, Peer Relationship Problems, Conduct Problems, Hyperactivity-Inattention), and a Prosocial Behaviour subscale. Items and response options were unmodified from the original scale, and the standard scoring metric applied: five items assessed each of the subscales, and Total Difficulties was computed by summing the 20 items from the four psychopathology subscales.

c. Supportive Relationships at home, at school and in the neighbourhood/community were assessed 


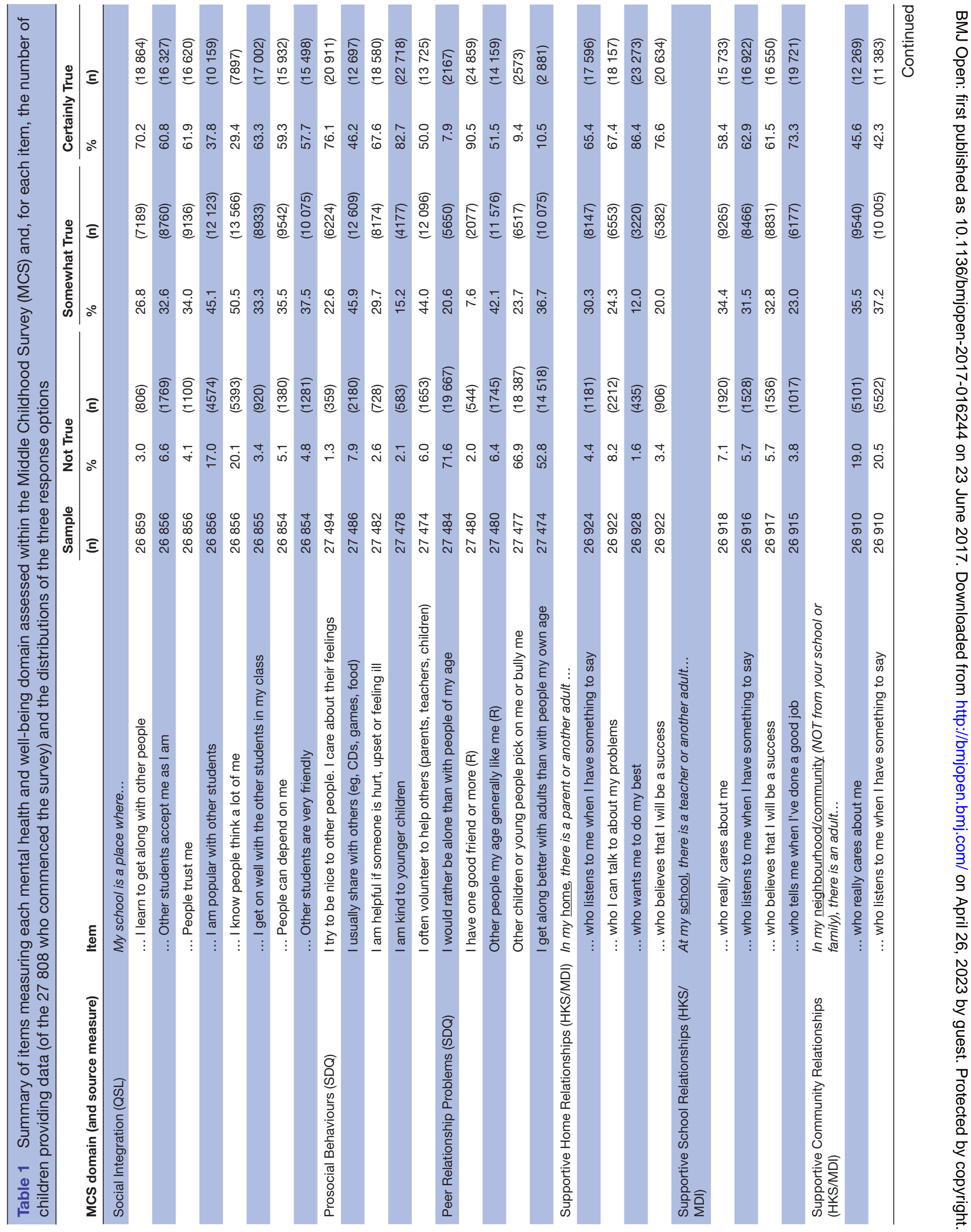




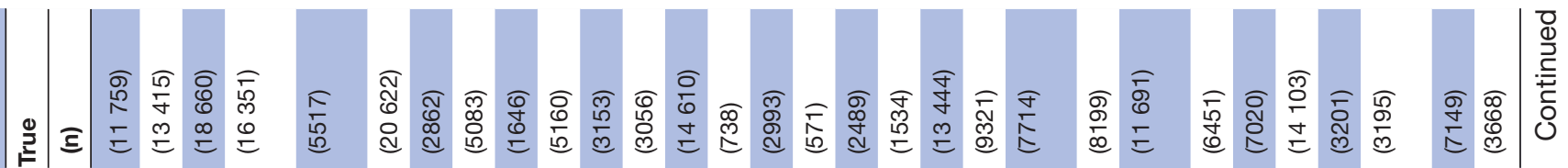

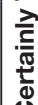

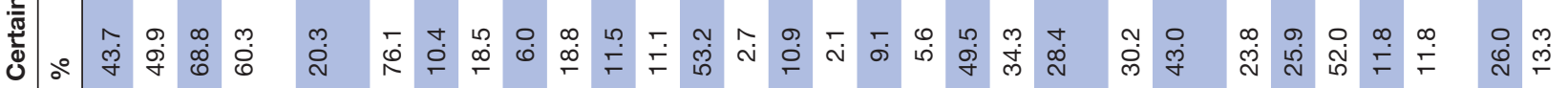

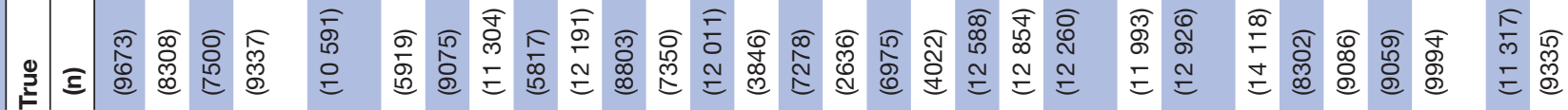
$\frac{\pi}{\frac{\pi}{3}}$ 至

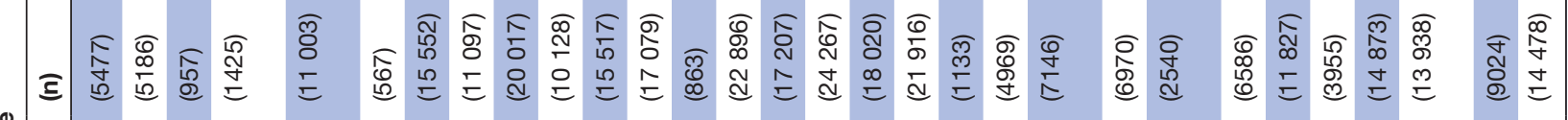
疍

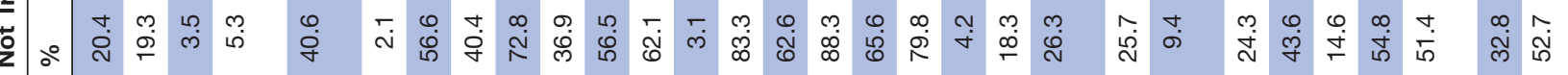

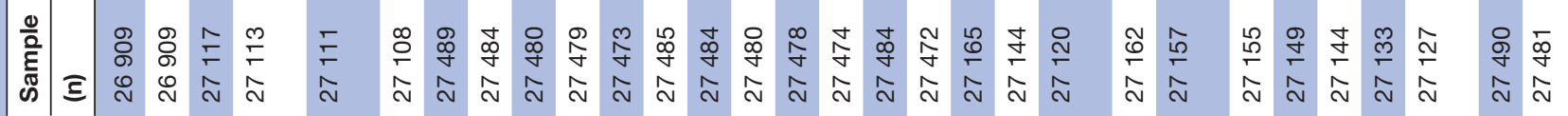
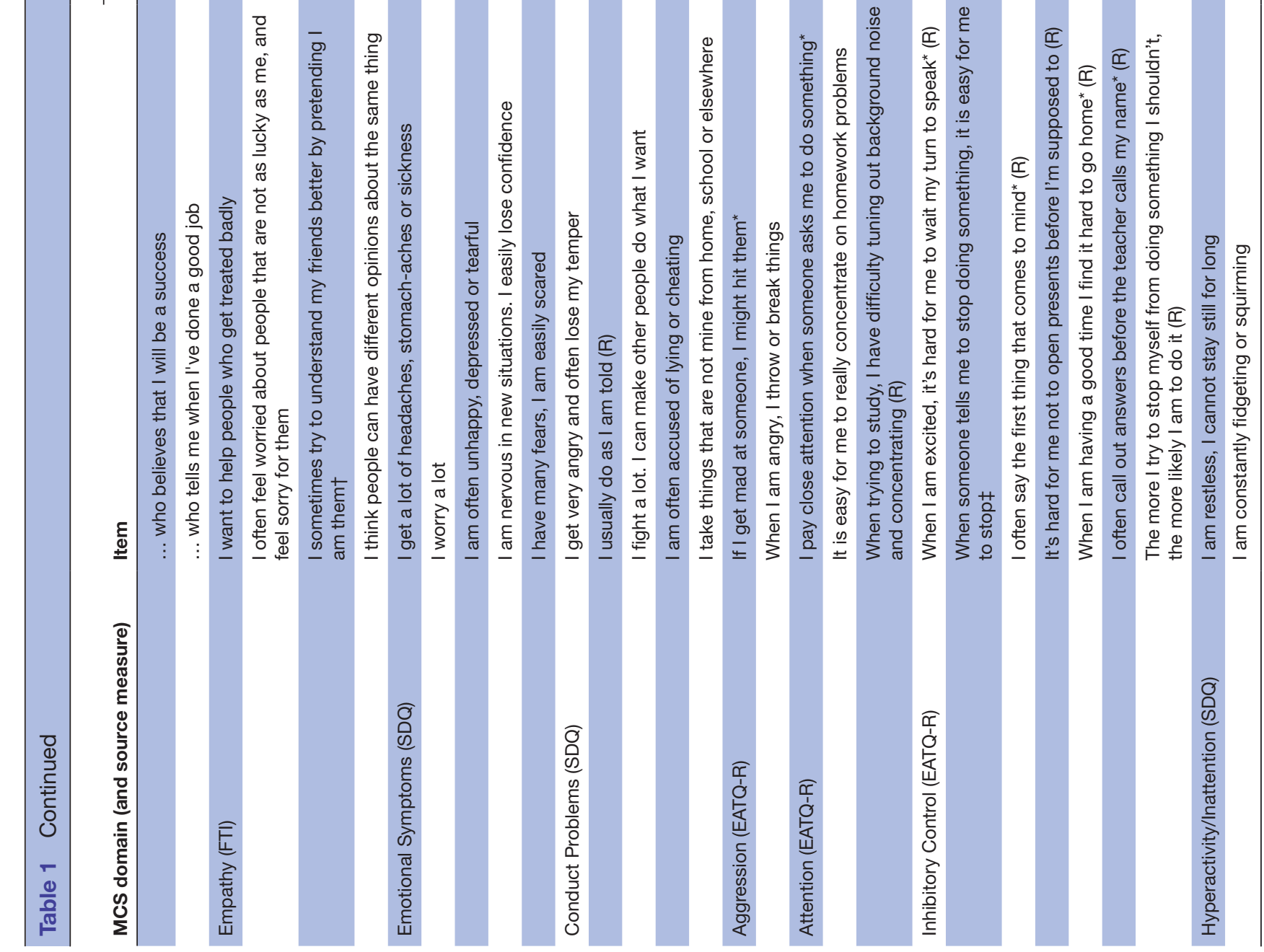

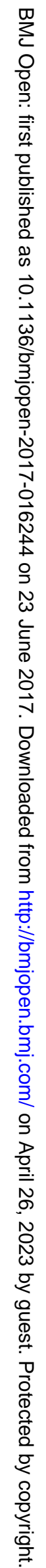




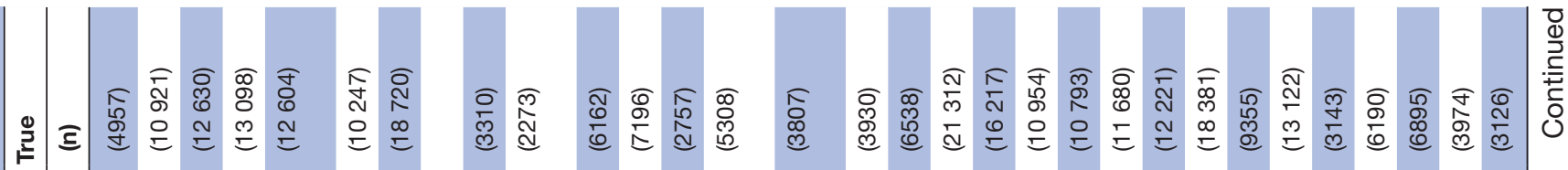

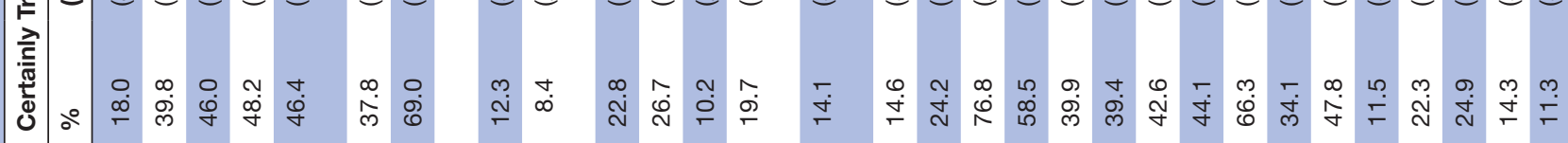

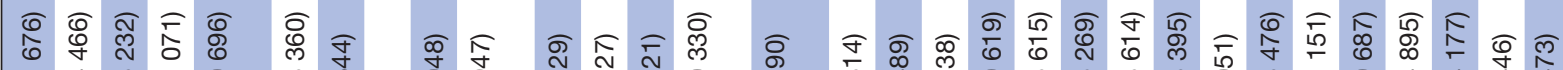

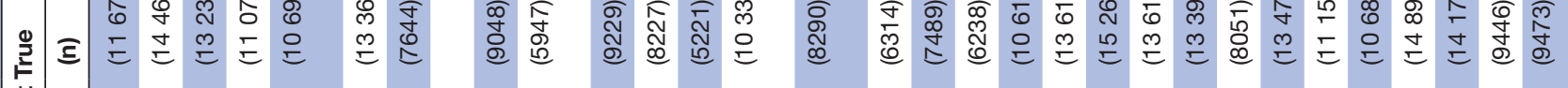
焉 峁

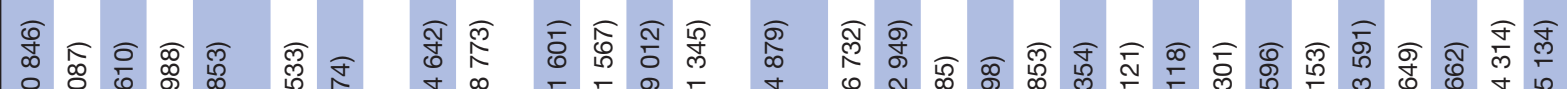
可

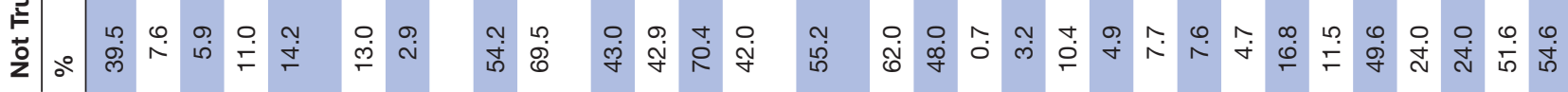

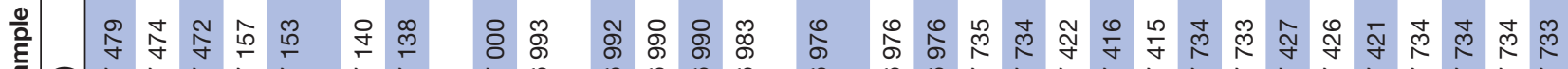

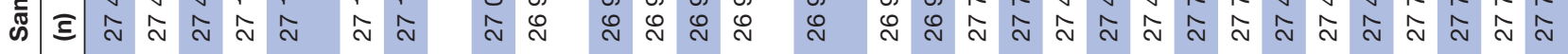
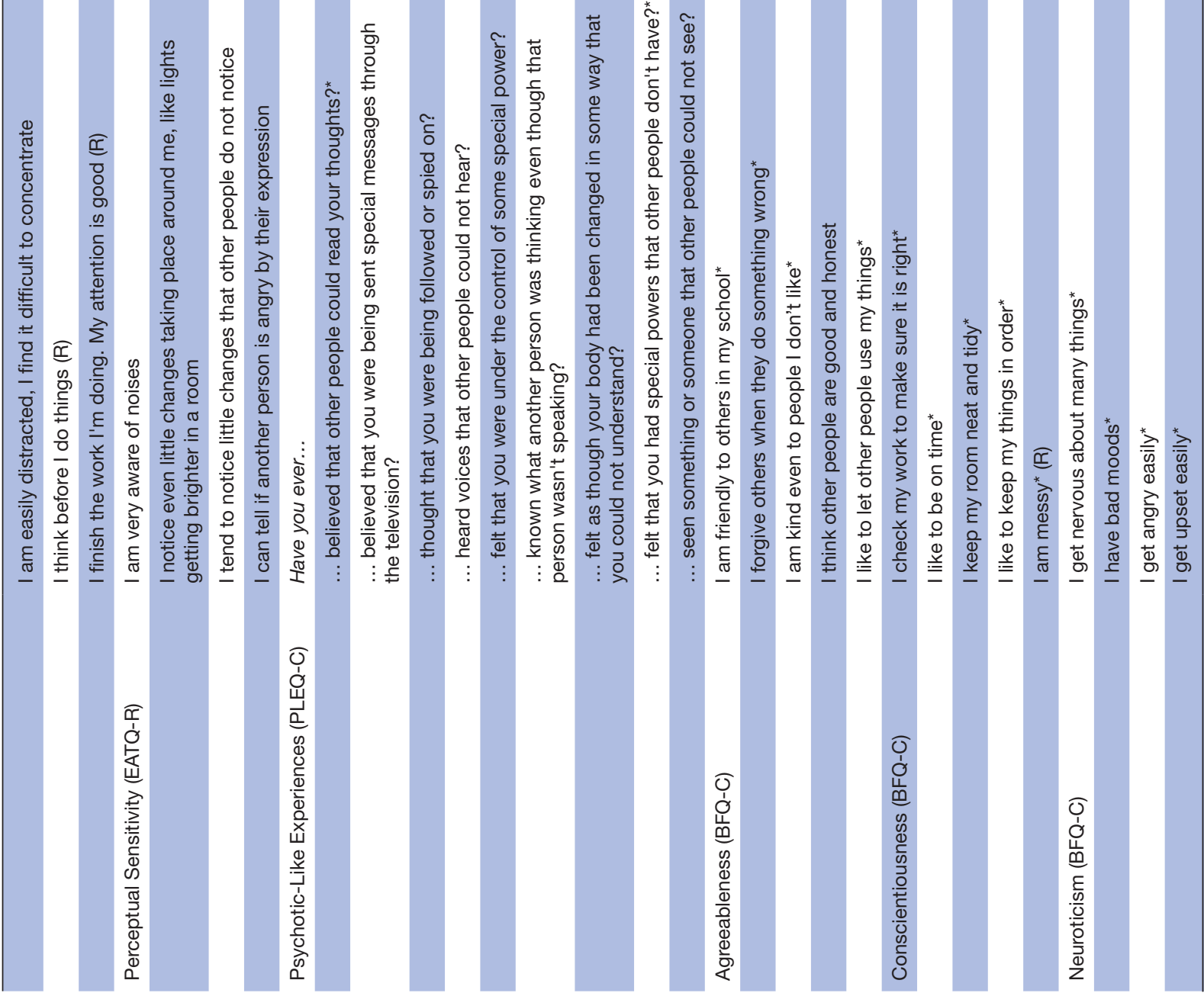


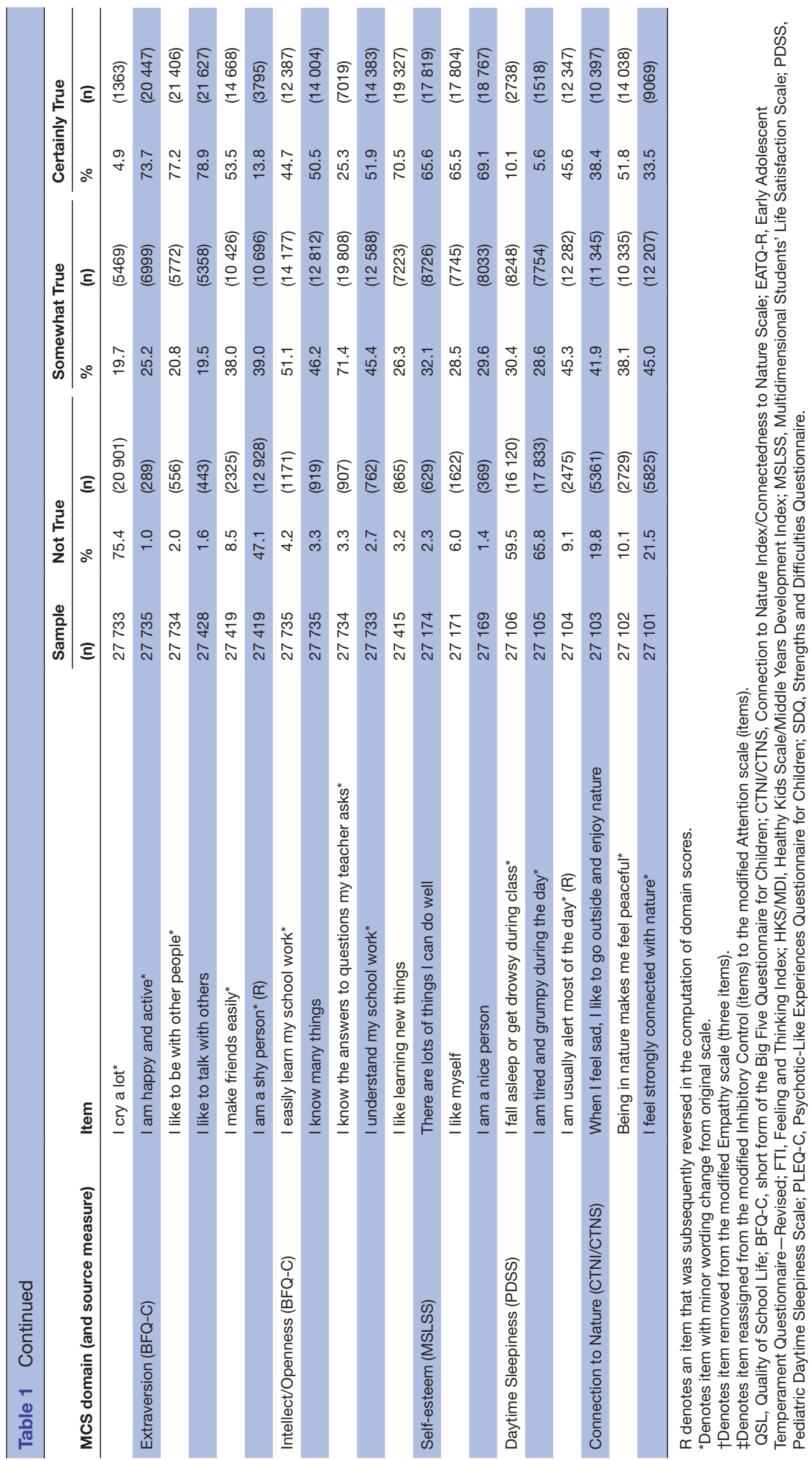

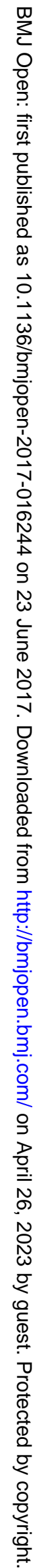


Table 2 Summary of selected demographic characteristics self-reported by the 27808 children completing the Middle Childhood Survey (MCS)

\begin{tabular}{|c|c|c|c|}
\hline \multirow[b]{2}{*}{ Demographic item } & \multirow{2}{*}{$\begin{array}{l}\text { Sample } \\
\text { (n) }\end{array}$} & \multicolumn{2}{|c|}{ Prevalence } \\
\hline & & $\%$ & (n) \\
\hline Age of child & 27808 & & \\
\hline 10 years or younger & & 0.5 & (135) \\
\hline 11 years & & 54.7 & (15 198) \\
\hline 12 years & & 44.1 & (12 259) \\
\hline 13 years or older & & 0.8 & $(216)$ \\
\hline Sex of child & 27808 & & \\
\hline Female & & 49.5 & (13 754) \\
\hline Male & & 50.5 & (14 054) \\
\hline $\begin{array}{l}\text { Number of people living in } \\
\text { child's home (main residence) }\end{array}$ & 27803 & & \\
\hline 3 or less & & 15.1 & $(4187)$ \\
\hline 4 & & 35.8 & (9948) \\
\hline 5 & & 27.8 & (7718) \\
\hline 6 or more & & 21.4 & (5950) \\
\hline $\begin{array}{l}\text { Main language spoken at } \\
\text { home }\end{array}$ & 27803 & & \\
\hline English & & 87.3 & (24 272) \\
\hline Arabic & & 1.9 & $(525)$ \\
\hline Vietnamese & & 1.3 & (365) \\
\hline Cantonese & & 1.1 & (296) \\
\hline Mandarin & & 1.0 & (278) \\
\hline Hindi & & 0.8 & (211) \\
\hline Tagalog & & 0.5 & (141) \\
\hline Spanish & & 0.4 & (99) \\
\hline Greek & & 0.2 & (49) \\
\hline Italian & & 0.1 & (35) \\
\hline Other & & 5.5 & (1532) \\
\hline $\begin{array}{l}\text { Child made use of MCS audio } \\
\text { recording }\end{array}$ & 27803 & 2.5 & (695) \\
\hline $\begin{array}{l}\text { Child received assistance from } \\
\text { an adult to complete survey }\end{array}$ & 27802 & 5.0 & (1398) \\
\hline
\end{tabular}

using 12 items (four per subscale) selected from the Healthy Kids Survey. ${ }^{15}$ These items included those (three per subscale) used in the Middle Years Development Index ${ }^{16}(M D I)$ plus an additional item for each subscale. Item wordings were unmodified from the MDI, but the 4-choice rating scale and averaged total score were replaced.

d. Sixteen items from four subscales in the Early Adolescent Temperament Questionnaire-Revised (EATQ-R $)^{17}$ assessed Attention (four items; selected from seven), Inhibitory Control (seven items; selected from 11), Perceptual Sensitivity (four items; selected from six) and Aggression (two items; selected from 11). The first three of these subscales comprise part of a measure of Effortful Control within the EATQ-R. Minor modifications to the wording of several items were made, and the original 5-point rating response scale and averaged total score replaced.

e. Empathy was assessed using four items from the 12item Feeling and Thinking Instrument ${ }^{18}$; item wording was unmodified, but the original 5-point rating response scale replaced.

f. Psychotic-like experiences were assessed with nine items from the Psychotic-Like Experiences Questionnaire for Children $^{819}$ (two with minor rewording from the original), with the original 3-choice response format retained.

g. Dimensions of personality (Extraversion, Neuroticism, Conscientiousness, Agreeableness and Intellect/Openness) were assessed using 25 items (5 per dimension) modified from an unpublished 30item short-form of the 65-item Big Five Questionnaire for Children (BFQ-C) ${ }^{20}$ supplied by the author (Barbaranelli, personal communication). Items were reworded to simplify the translation from Italian to English. Following pilot testing in 2014, 5 of the 25 items were replaced with other candidates, adapted from the full BFQ-C, to improve psychometric properties. The original 5-point rating response scale was replaced.

h. Self-esteem was measured with three unmodified items from the 7-item Self-Satisfaction subscale of the Multidimensional Students' Life Satisfaction Scale. ${ }^{21}$ The original 4-choice response scale and averaged total score were replaced.

i. Daytime sleepiness was assessed with three items selected from the 8-item Pediatric Daytime Sleepiness Scale, ${ }^{9}$ with minor rewording of items and replacement of the original 5-point response scale.

j. Connection to Nature (or, children's engagement with the natural environment) was measured with three items; two were modified from the 7-item Enjoyment of Nature subscale of the Connection to Nature Index $x^{22}$ and one modified from the 14-item Connectedness to Nature Scale. ${ }^{23}$ The original 5-point rating scales of both measures were replaced.

\section{FINDINGS TO DATE}

\section{Sample characteristics}

A flow diagram summarising the stages of school and child recruitment is provided in figure 1 ; this also details the reasons for non-participation of schools ${ }^{\mathrm{i}}$ and/or children in the MCS. Of the 2371 NSW schools with an eligible year 6 student enrolment, $829(35.0 \%)$ administered the MCS. These schools provided a total enrolment of 32389 children who were invited to complete the MCS (representing $36.6 \%$ of year 6 enrolments in NSW schools). Among these, 27808 participated in the MCS (85.9\% of invited children). Parent and child opt-outs totalled $4.3 \%$ of eligible children (the remaining $9.9 \%$ did not participate for other reasons detailed in figure 1). The mean age 
Table 3 Demographic characteristics of MCS participating schools relative to all NSW schools with a year 6 student enrolment (unweighted and weighted by enrolment)

\begin{tabular}{|c|c|c|c|c|}
\hline \multirow{3}{*}{$\begin{array}{l}\text { Demographic } \\
\text { measure }\end{array}$} & \multicolumn{2}{|l|}{ Unweighted averages } & \multicolumn{2}{|l|}{ Weighted averages* } \\
\hline & NSW schools $(n=2371)$ & MCS schools $(n=829)$ & NSW schools (weighted) & MCS schools (weighted) \\
\hline & $\%(n)$ & $\%(n)$ & $\%(n)$ & $\%(n)$ \\
\hline \multicolumn{5}{|l|}{ School sector: } \\
\hline Government & $67.9(1609)$ & $67.1(556)$ & 67.4 & 66.6 \\
\hline Non-government & $32.1(762)$ & $32.9(273)$ & 32.6 & 33.4 \\
\hline \multicolumn{5}{|l|}{ Geographical location: } \\
\hline Metropolitan & $59.9(1421)$ & $62.4(517)$ & 76.3 & 76.2 \\
\hline Rural & 37.7 (894) & $35.8(297)$ & 23.1 & 23.3 \\
\hline Remote & $1.8(43)$ & $1.4(12)$ & 0.4 & 0.5 \\
\hline \multirow[t]{2}{*}{ Very remote } & $0.5(13)$ & $0.4(3)$ & 0.1 & 0.1 \\
\hline & Mean (SD) & Mean (SD) & Mean (SD) & Mean (SD) \\
\hline ICSEA score & $1007.7(93.5)$ & $1002.8(92.4)$ & $1033.2(87.1)$ & $1026.5(84.1)$ \\
\hline \multicolumn{5}{|c|}{ Socioeducational quartiles based on ICSEA (\%): } \\
\hline Lowest & $28.8(22.3)$ & $29.6(22.3)$ & $23.5(20.3)$ & $24.6(20.5)$ \\
\hline Lower-Middle & $24.3(9.3)$ & $24.6(8.4)$ & $22.9(9.3)$ & $23.6(8.7)$ \\
\hline Higher-Middle & $23.4(8.8)$ & $23.5(8.7)$ & $24.7(7.8)$ & $24.9(7.8)$ \\
\hline Highest & $23.5(21.7)$ & $22.4(20.5)$ & $29.0(23.4)$ & $26.9(21.7)$ \\
\hline Proportion LBOTE (\%) & $23.3(27.3)$ & $23.7(27.4)$ & $31.1(30.3)$ & $30.2(30.1)$ \\
\hline $\begin{array}{l}\text { Proportion Indigenous } \\
\text { (\%) }\end{array}$ & $9.1(13.7)$ & $9.5(13.4)$ & $6.0(9.2)$ & $6.3(9.1)$ \\
\hline Proportion female (\%) & $48.6(9.3)$ & $48.8(7.1)$ & $48.5(10.3)$ & $48.7(7.0)$ \\
\hline
\end{tabular}

${ }^{*}$ To estimate the proportions of children in NSW and MCS schools described by each demographic measure, weighting was applied based on the number of year 6 students (NSW schools) and MCS participants in each school (MCS schools); see Australian Curriculum, Assessment and Reporting Authority [2015], ICSEA 2014: Technical Report. http//www.acara.edu.au/_resources/ICSEA_2014_technical_report.pdf). ICSEA , Index of Community Socio-Educational Advantage 2014 (this score is derived from a number of variables, including parental school and non-school education and occupation, the school's geographical location and proportion of Indigenous students); LBOTE , Language Background Other Than English; MCS, Middle Childhood Survey; NSW, New South Wales.

of participating children was 11.5 years (SD 0.5); other demographic information on participants is summarised in table 2. Average survey completion time was $16.5 \mathrm{~min}$, with $90 \%$ of children completing within $7-50$ min.

The representativeness of participating schools and children relative to the respective state population was estimated using publicly accessible national schoollevel data on enrolment and sociodemographic indices. Table 3 compares the demographic characteristics of all NSW schools and MCS participating schools, first as distributions of unweighted data, and second as distributions after weighting by year 6 enrolment and number of MCS participants per school. The 829 schools that participated in the MCS were comparable on a range of demographic indices to the total population of NSW schools with a year 6 enrolment; all figures reported for the MCS participating schools (both unweighted data and weighted estimates) lie within $\sim 2 \%$ of NSW rates.

\section{Item responses and scale distributions}

Table 1 summarises the distribution of children's responses on all MCS items, grouped according to the constructs they measured. Similar data, reported separately for girls and boys, are provided in online supplementary table 1-X. The total number of children reporting each item ranged from a minimum of 26853 (3.4\% missing) to 27735 (0.3\% missing). An unknown portion of these missing responses related to data server capacity issues encountered early in the MCS administration period and resolved promptly by the IT contractor.

For each MCS construct, table 4 (and online supplementary table 2-X) provides descriptive statistics (including number of children providing complete data on the scale, means, $\mathrm{SD}$, minima and maxima), internal consistency coefficients (ordinal $\alpha$-coefficients ${ }^{24}$ ) and scores corresponding to a range of percentiles in the sample distribution (ie, 10th, 25th, 50th, 75th, 90th). These percentiles were adapted from those reported for the $\mathrm{AEDC}^{6}$ (where scores in the lowest 10th percentile were described as 'developmentally vulnerable', between the 10th and 25th percentiles as 'developmentally at risk' and between the 25th-50th and $>50$ th percentiles as two bands of 'developmentally on track' scores), with the 75th and 90th percentiles added to accommodate the bidirectional orientation of MCS scales. 


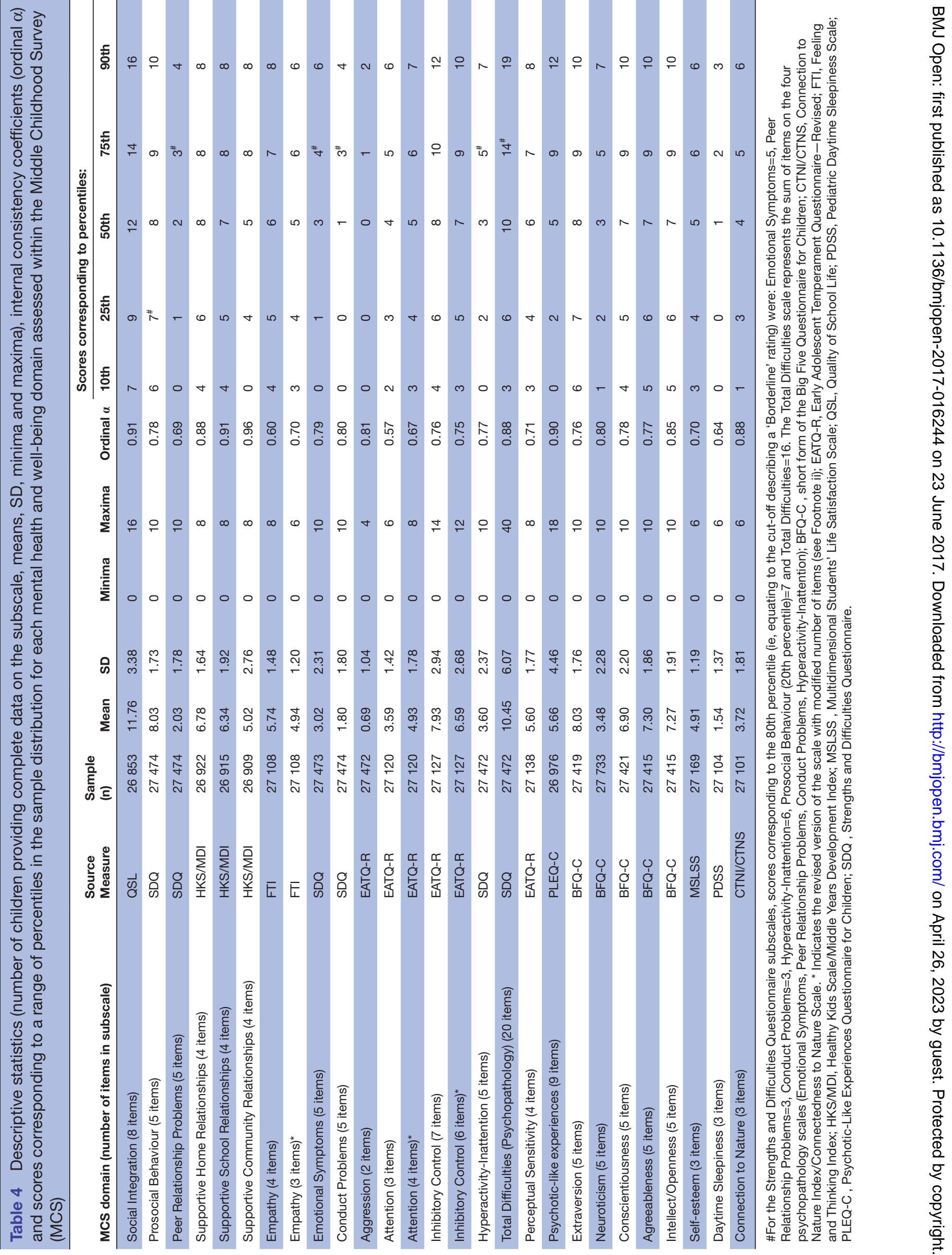


The total number of children providing complete scale data ranged from a minimum of 26853 (3.4\% missing) to a maximum of 27733 (0.3\% missing). On average, children in the sample scored in the range reflecting healthier or more developmentally mature functioning on each construct, but the population distribution spanned the full range of possible scores on every scale. For most scales, each of the specified percentiles was associated with a unique score on the scale even at the extremes (10th and 90th percentiles), indicating a lack of ceiling/floor effects in measurement. The ordinal $\alpha$-coefficients indicated adequate reliability for all MCS domains; for the two scales with the lowest $\alpha$-coefficients (Attention and Empathy), minor modifications to these scales ${ }^{\mathrm{ii}}$ improved the coefficients and these revised scales are also summarised in the Tables.

\section{Profile of mental health and well-being in the MCS cohort}

High mean total scores on Social Integration, Prosocial Behaviour, Empathy, Attention, Inhibitory Control and Self-esteem were indicative of healthier functioning or developmentally more mature capacities for the majority of children in the sample. High mean scores also indicated most children's access to Supportive Relationships at Home, School and in the Community, and engagement with the natural environment (Connection to Nature). Low mean total scores on Peer Relationship Problems, Emotional Symptoms, Conduct Problems, Aggression, Hyperactivity-Inattention, Total Difficulties (psychopathology) and Daytime Sleepiness were further indicative of healthy functioning among the majority of children in the MCS cohort. Nonetheless, on all scales, there were children who displayed less healthy or developed functioning or lacked access to supports (eg, $13.2 \%$ of children reported a lack of any supportive relationship with an adult in their community or neighbourhood).

Other scales in the MCS measured unusual thoughts or perceptual experiences that, although more prevalent in children with neurodevelopmental disorders and those who later develop adult psychiatric illness, are nonetheless common in child populations ${ }^{25}$ : a majority of children $(52.2 \%)$ responded 'Certainly True' to at least one of the nine PLE items, and the high mean total scores on Perceptual Sensitivity indicated that most children also reported sensitivity to slight, low-intensity stimulation in the environment. With respect to personality dimensions, on average, children produced higher scores on Extraversion, Conscientiousness, Agreeableness and Openness/ Intellect scales (reflecting a tendency to avoid endorsement of the 'Not True' response), and lower scores on Neuroticism, relative to the scale range of each construct.

Pearson's correlation coefficients indicating the pattern, direction and strength of associations (small 0.1 ; medium 0.3; large 0.5$)^{26}$ between the MCS scales are provided in online supplementary table 3-X (with associations for girls and boys provided in online supplementary table 4-X). Almost all constructs related significantly in this large sample, with almost half $(45 \%)$ of the associations of medium or large magnitude.

\section{Comparison with published data}

Direct comparison of MCS responses with published data on the SDQ and PLE scales from general population samples was afforded by use of the original items, response options and scoring methods for these scales. Mean scores on Prosocial Behaviour and Conduct Problems aligned closely with Australian self-report SDQ norms published in 2005 by age and sex (based on a Victorian community sample of 553 children aged 11-17 years, including 292 children aged 11-13 years ${ }^{27}$, and were slightly greater in our sample for Total Difficulties, Emotional Symptoms, Peer Relationship Problems and Hyperactivity-Inattention. This pattern of change in means over the decade between the 2005 study and ours appears consistent with the small, but significant, increases observed between 2007 and 2012 in the self-report subscale means for Total Difficulties, Emotional Symptoms, Peer Relationship Problems and Hyperactivity-Inattention (but a decrease in Conduct Problems) in nationally representative New Zealand samples of children aged $12-15$ years, ${ }^{28}$ and with a similar increase in Emotional Symptoms and decrease in Conduct Problems between 2009 and 2014 in English community samples of children aged 11-13years. ${ }^{29}$ The mean PLE score in the MCS sample aligned closely with that reported previously for a relatively deprived innercity London, UK, community sample aged 9-12 years ${ }^{19}$ using these same nine items, although the overall prevalence of a 'Certainly True' to at least one of the nine items in the MCS $(52.2 \%)$ was lower than that obtained in the London sample $(66.0 \%){ }^{8}$

For the SDQ psychopathology scales, table 5 (and online supplementary table 5-X) indicates the proportions of children falling within the normal (defined as $\sim 80 \%)$, borderline $(\sim 10 \%)$ and abnormal $(\sim 10 \%)$ categories defined for the SDQ based on the UK population norms, as well as the proportions of children scoring in each category of the more recent four-level solution (close to average $\sim 80 \%$, slightly raised $\sim 10 \%$, high $\sim 5 \%$, very high $\sim 5 \%)$. Several departures from these figures are notable (eg, $91 \%$ of children scored in the normal range of the Prosocial Behaviour scale, and only $67 \%$ of children scored 'close to average' on the Peer Relationship Problems scale); the application of the established scoring metrics derived on the UK population samples may overestimate the prevalence of problems with peers and underestimate vulnerability on Prosocial Behaviour among Australian children aged approximately 11 years.

Capacity for direct comparison of MCS data with published data from similar large, general population samples was limited for the other scales owing to modification from the original response formats to a standard three-choice format, adoption of a standard method of summed total scores for all scales and by minor alterations to the wording of some items. Despite these modifications, consistencies with data from other 
Table 5 Distribution of the Strengths and Difficulties Questionnaire (SDQ) categories on each subscale as defined by the traditional three-level and more recent four-level solutions

\begin{tabular}{|c|c|c|c|c|c|c|c|c|c|}
\hline \multirow[b]{2}{*}{ SDQ subscale } & \multirow{2}{*}{$\begin{array}{l}\text { Sample } \\
\text { (n) }\end{array}$} & \multicolumn{2}{|c|}{ Normal } & \multicolumn{2}{|c|}{ Borderline } & \multicolumn{2}{|c|}{ Abnormal } & & \\
\hline & & $\%$ & (n) & $\%$ & (n) & $\%$ & (n) & & \\
\hline Emotional Symptoms & 27473 & 84.6 & (23 233) & 6.5 & (1778) & 9.0 & (2462) & & \\
\hline Peer Relationship Problems & 27474 & 81.2 & (22 318) & 13.8 & (3789) & 5.0 & (1367) & & \\
\hline Conduct Problems & 27474 & 83.2 & (22 870) & 7.7 & (2125) & 9.0 & (2479) & & \\
\hline Hyperactivity-Inattention & 27472 & 78.0 & (21 416) & 9.5 & (2613) & 12.5 & (3443) & & \\
\hline Prosocial Behaviour & 27474 & 90.7 & (24 908) & 5.6 & (1543) & 3.7 & (1023) & & \\
\hline \multirow[t]{2}{*}{ Total Difficulties } & 27472 & 79.9 & (21 943) & 11.6 & $(3180)$ & 8.6 & (2349) & & \\
\hline & Sample & \multicolumn{2}{|c|}{ Close to average } & \multicolumn{2}{|c|}{ Slightly raised } & \multicolumn{2}{|c|}{ High } & \multicolumn{2}{|c|}{ Very high } \\
\hline SDQ subscale & (n) & $\%$ & (n) & $\%$ & (n) & $\%$ & (n) & $\%$ & (n) \\
\hline Emotional Symptoms & 27473 & 75.2 & (20 659) & 9.4 & (2574) & 6.5 & (1778) & 9.0 & (2462) \\
\hline Peer Relationship Problems & 27474 & 66.9 & (18 368) & 14.4 & (3950) & 8.9 & (2445) & 9.9 & (2711) \\
\hline Conduct Problems & 27474 & 83.2 & (22 870) & 7.7 & (2125) & 4.6 & (1258) & 4.4 & (1221) \\
\hline Hyperactivity-Inattention & 27472 & 78.0 & (21 416) & 9.5 & (2613) & 6.2 & (1713) & 6.3 & (1730) \\
\hline Prosocial Behaviour* & 27474 & 90.7 & (24 908) & 5.6 & (1543) & 2.3 & (633) & 1.4 & (390) \\
\hline Total difficulties & 27472 & 75.8 & (20 815) & 10.6 & (2923) & 5.0 & (1385) & 8.6 & (2349) \\
\hline
\end{tabular}

*For the Prosocial Behaviour subscale, the four-level classification labels are instead 'close to average', 'slightly lowered', 'low' and 'very low'.

developed nations were apparent: children's reports of Social Integration at school were similar to those reported previously in primary school samples in Australia ${ }^{14}$ and Hong Kong ${ }^{30}{ }^{31}$; response patterns on the EATQ-R scales (Attention, Inhibitory Control, Perceptual Sensitivity and Aggression) aligned with data from a community sample of 1055 Dutch $^{32}$ school students of similar age and access to Supportive Relationships at Home, School and in the Community was similar to that reported for a community sample of Canadian fourth-grade school children ( 2 years younger than our sample). ${ }^{16}$ The pattern of responses on the Big Five personality constructs was also consistent with that reported for an Australian sample of 268 children aged $10-12$ years ${ }^{33}$ using the full 65 -item version of the BFQ-C. ${ }^{20}$

\section{Sex differences}

Supplementary table 2-X provides the item responses and scale distributions separately for girls and boys, and the eta squared $\left(\eta^{2}\right)$ estimate of the effect size of sex differences for each scale. Statistically significant differences between the scores of girls and boys were apparent on all scales, although the magnitude of these differences was small (sex effects on all scales accounted for $\leq 2 \%$ of total variance, except for the small-to-medium effects, explaining $4 \%$ of total variance, on Prosocial Behaviour and Aggression). Across the domains, girls' mean scores were greater than those of boys' on Social Integration, Prosocial Behaviour, Supportive Relationships at Home, School and in the Community, Empathy, Emotional Symptoms, Attention and Inhibitory Control, Perceptual Sensitivity and Psychotic-Like Experiences, Neuroticism, Conscientiousness, Agreeableness, Self-esteem and
Connection to Nature. Conversely, boys' mean scores were greater on Peer Relationship Problems, Conduct Problems and Aggression, Hyperactivity-Inattention, Total Difficulties (psychopathology), Extraversion, Openness/Intellect and Daytime Sleepiness.

\section{STRENGTHS AND LIMITATIONS}

The major strengths of the MCS are twofold. First, the MCS provides a comprehensive assessment of psychosocial and behavioural constructs reflecting mental health and well-being in a large sample of 27808 children aged approximately 11 years (representing $31.4 \%$ of eligible NSW students), which is representative of the NSW population on a range of demographic variables (table 3). Second, the MCS incorporated measures of both personal competencies and vulnerabilities, and the scores on every scale spanned the entire range of possible scores, providing capacity to examine patterns of both strength and vulnerability in the population. This also facilitates the identification of determinants of average mental health in the population (rather than focusing on the extreme ends of the distribution), which will provide important information to guide the development and implementation of universal mental health promotion programmes alongside targeted approaches for vulnerable children. ${ }^{34}$ Data were collected by self-report, providing access to the child's own perspective on their experiences, which may be particularly important for phenomena that are less readily judged by other informants. Finally, an important strength of the MCS lies in being embedded within planned record linkages of the NSW-CDS, ${ }^{5}$ incorporating intergenerational records on health, education, 
child protection and justice contacts, and with the AEDC ${ }^{6}$ assessment of early childhood development at age 5 years. This will allow responses on the MCS to be interpreted in the context of longitudinal data that is subject to minimal selection bias and will permit investigation of multiple factors associated with outcomes of low prevalence, and/ or of relevance to cultural, geographic, socioeconomic or other subgroups within the population.

A number of limitations of the MCS must be acknowledged. Despite the large sample obtained being representative of the population from which it was drawn, failure to obtain data from all individuals will have the consequence of limiting data available to the current and future record linkages conducted within the NSW-CDS framework. The MCS is further limited by a lack of parent and/or teacher reports to supplement children's self-report. Only moderate agreement is typical between child, parent and teacher ratings of children's mental health and well-being, indicating that the ratings of informants are not interchangeable. ${ }^{35}$ Furthermore, the MCS was limited in coverage both in terms of domains assessed and the number of items assessing each domain; these were constrained by the limited time available within schools for survey administration, lack of parent and/or teacher reports on additional aspects of children's experiences and by the sensitivities associated with assessing domains perceived as potentially distressing for the child. For example, information on potentially important constructs such as bullying/victimisation experiences or physical health (including participation in health/ leisure activities and nutrition) was not obtained. Similarly, our assessment of Aggression was limited to only two items, which do not capture the full complexity and multidimensional nature of this construct. And, while aspects of the cognitive control of emotions and behaviours were measured, no assessment of cognitive capacities was obtained; linkage of the MCS with education records on academic progress within the NSW-CDS will provide some index of these capacities. The lack of capacity to compare MCS data directly with published data from similar large, general population samples was limited for most scales owing to modification from the original response formats to a standard three-choice format, adoption of a standard method of summed total scores for all scales and by minor alterations to the wording of some items. On several scales, including the personality dimensions, the restriction of responses to three categories may have artificially reduced variability among participants, with $<10 \%$ of children electing one of the three options on several items. Prior to MCS administration, psychometric testing of our English translation of the short-form Italian BFQ-C ${ }^{20}$ measure of personality dimensions was conducted using the data obtained from 645 children during pilot testing of the survey in 2014, with subsequent revision of 5 of the 25 items assessing these dimensions in the MCS. A manuscript reporting the validity and reliability of this revised measure is currently being drafted for publication.

\section{FUTURE PLANS}

Further structural analysis of the MCS data is underway to derive the most psychometrically robust measures of each mental health and well-being domain. The multiagency, intergenerational linkage of the MCS data with other health, education, child protection, justice and AEDC records took place late in 2016. This will be used to elucidate patterns of risk and protection across early and middle child development, and also provide a foundation for future record linkages in the cohort that will track mental and physical health, social and educational/ occupational outcomes into adolescence and early adulthood. The record linkage will also incorporate data on the quality and extent of implementation of mental health promotion and early intervention programmes in NSW schools, affording an opportunity to examine how delivery of such programmes may modify individual pathways of social, emotional and behavioural function between early and middle childhood. This work will assist in determining appropriate universal mental health promotion and targeted early intervention programmes that can bolster strengths and mitigate risks in order to maximise healthy development.

${ }^{\mathrm{i}}$ The reasons for principal opt-outs were not assessed systematically, but among those who volunteered this information, these were predominantly that the school was too busy to participate or already committed to other research participation.

ii For the Empathy construct, the 'alpha if item removed' value indicated improvement of the $\alpha$-coefficient following removal of one of the four items. For the Attention construct, alpha was improved by relocating an item from the Inhibitory Control scale that has been previously demonstrated to load with the Attention items in published factor analysis of the full scale. ${ }^{32}$ These modifications are indicated by $\ddagger$ in table 1 (and online supplementary table $1-\mathrm{X}$ ), and detail on the revised scales included in table 4 (and online supplementary table 2-X).

\footnotetext{
Author affiliations

${ }^{1}$ School of Psychiatry, University of New South Wales, Sydney, New South Wales, Australia

${ }^{2}$ Neuroscience Research Australia, Sydney, New South Wales, Australia

${ }^{3}$ School of Psychology, Australian Catholic University, Brisbane, Queensland, Australia

${ }^{4}$ School of Social Sciences, University of New South Wales, Sydney, New South Wales, Australia

${ }^{5}$ Justice Health \& Forensic Mental Health Network, Sydney, New South Wales, Australia

${ }^{6}$ Telethon Kids Institute, University of Western Australia, Perth, Western Australia, Australia

${ }^{7}$ School of Public Health, University of Adelaide, Adelaide, South Australia, Australia ${ }^{8}$ School of Psychology, University of Newcastle, Newcastle, New South Wales, Australia
} 
${ }^{9}$ School of Education, University of Newcastle, Newcastle, New South Wales, Australia

${ }^{10}$ NSW Department of Education, Sydney, New South Wales, Australia

${ }^{11}$ Department of Psychiatry, School of Clinical Sciences, Monash University, Melbourne, Victoria, Australia

Correction notice This paper has been amended since it was published Online First. Owing to a scripting error, some of the publisher names in the references were replaced with 'BMJ Publishing Group'. This only affected the full text version, not the PDF. We have since corrected these errors and the correct publishers have been inserted into the references.

Acknowledgements The authors gratefully acknowledge the support provided for the MCS administration by the NSW Department of Education (represented by Robert Stevens, Susan Harriman and Liliana Ructtinger), the Catholic Education Commission NSW (represented by Peter Grace), the Association of Independent Schools of NSW (represented by Robyn Yates and Susan Wright) and other stakeholder organisations including the NSW Primary Principals' Association, NSW Teachers Federation, Independent Education Union NSW/ACT, Federation of Parents and Citizens Associations of NSW, Council of Catholic School Parents, NSW Parents Council, Isolated Children's Parents' Association and the NSW Aboriginal Education Consultative Group. The authors also acknowledge the contributions of all members of the NSW-CDS Scientific Committee who oversaw the project: Vaughan Carr (Chairman), Miles Bore, Sally Brinkman, Marilyn Chilvers, Kimberlie Dean, Katherine Dix, Luke Duffy, Melissa Green, Felicity Harris, Allyson Holbrook, Maina Kariuki, Kristin Laurens, Rhoshel Lenroot, Kim Robinson, Maxwell Smith, Titia Sprague, Robert Stevens, Michael Tarren-Sweeney, Stacy Tzoumakis and Megan Williams; as well as the support for MCS administration provided by former members of the Committee: Stephanie Dick, Philip Hull, Luming Luo, Stephen Lynn, Brooke McIntyre and Alessandra Raudino. The authors thank the IT contractor, Multi-Media Concepts (Cary Redstone and Jarratt Holliday), for their provision of the online survey. The information and perspectives expressed in the manuscript do not necessarily reflect the views of these contributing organisations or individuals.

Collaboration Initial data analyses and publications on Middle Childhood Survey and linked data were generated primarily by the authors of this paper and other members of the Scientific Committee, named in the Acknowledgements section, who oversaw the New South Wales Child Development Study (NSW-CDS). The research team is open to research collaborations with other scientists, within restrictions placed on the use of linked data according to strict privacy legislation; interested parties should contact the Lead Investigator of the NSW-CDS (Vaughan Carr: v.carr@unsw.edu.au) with their expressions of interest.

Contributors In line with the ICMJE authorship guidelines, KRL, ST, KD, SAB, MB, RKL, MS, AH, KMR, RS, FH, VJC and MJG made substantial contributions to the conception or design of the work. KRL, ST, KD, FH, VJC and MJG made substantial contributions to the acquisition, analysis and interpretation of the data. KRL, ST, KD, $S A B, M B, R K L, M S, A H, K M R, R S$, FH, VJC and MJG contributed to the drafting of the manuscript and/or revising of the manuscript. KRL, ST, KD, SAB, MB, RKL, MS, AH, KMR, RS, FH, VJC and MJG have given final approval of the version to be published, and agree to its accuracy.

Funding This work was supported by funding from a National Health and Medical Research Council of Australia (NHMRC) Project Grant (1058652); an Australian Research Council Linkage Project (LP110100150), with the NSW Ministry of Health, NSW Department of Education and the NSW Department of Family and Community Services representing the Linkage Project Partners; and an Australian Rotary Health Research Grant (RG104090). KRL, FH and VJC were supported by funding from the Schizophrenia Research Institute, Australia, using infrastructure funding from the NSW Ministry of Health. MJG was supported by an NHMRC R.D. Wright Biomedical Career Development Fellowship (1061875). KD was supported by the Justice Health \& Forensic Mental Health Network, NSW. SAB was supported by an NHMRC Early Career Fellowship (1090146). KMR received scholarship funding from the Australian Postgraduate Award scheme, the Faculty of Education and Arts at the University of Newcastle and the Australian Research Council Linkage Project (LP110100150).

Competing interests None declared.

Ethics approval Ethical approval was obtained from the University of New South Wales Human Research Ethics Committee (UNSW HREC reference HC14307) and the NSW Department of Education State Education Research Applications Process (reference 2015082); the use of opt-out consent procedures (for parents and children) was guided by the Australian National Health and Medical Research Council National Statement of Ethical Conduct in Human Research (chapter 2.3), which specifies conditions under which these procedures are appropriate. Access to publicly available school-level data on enrolment and demographic indices for the 2371 eligible NSW schools (used to estimate the representativeness of participating schools and children) was acquired from the Australian Curriculum, Assessment and Reporting Authority under UNSW HREC approval (reference HC14348).

Provenance and peer review Not commissioned; externally peer reviewed.

Data sharing statement Strict privacy legislation places restrictions on the use of linked data; scientists interested in using the data in collaboration with the NSWCDS Investigators should contact the Lead Investigator of the NSW-CDS (Vaughan Carr: v.carr@unsw.edu.au) with their expressions of interest.

Open Access This is an Open Access article distributed in accordance with the Creative Commons Attribution Non Commercial (CC BY-NC 4.0) license, which permits others to distribute, remix, adapt, build upon this work non-commercially, and license their derivative works on different terms, provided the original work is properly cited and the use is non-commercial. See: http://creativecommons.org/ licenses/by-nc/4.0/

(c) Article author(s) (or their employer(s) unless otherwise stated in the text of the article) 2017. All rights reserved. No commercial use is permitted unless otherwise expressly granted.

\section{REFERENCES}

1. Collins WA. Development during middle childhood: the years from six to twelve. Washington, D.C.: National Academies, 1984

2. Zembar MJ, Blume LB. Middle Childhood Development: a Contextual Approach. Upper Saddle River, N.J: Merrill/Pearson, 2009.

3. Costello EJ, Copeland W, Angold A. The Great Smoky Mountains Study: developmental epidemiology in the southeastern United States. Soc Psychiatry Psychiatr Epidemiol 2016;51:639-46.

4. Poulton R, Moffitt TE, Silva PA. The Dunedin Multidisciplinary Health and Development Study: overview of the first 40 years, with an eye to the future. Soc Psychiatry Psychiatr Epidemiol 2015;50:679-93.

5. Carr VJ, Harris F, Raudino A, et al. New South Wales Child Development Study (NSW-CDS): an australian multiagency, multigenerational, longitudinal record linkage study. BMJ Open 2016;6:e009023.

6. Brinkman SA, Gregory TA, Goldfeld S, et al. Data resource profile: the australian early development index (AEDI). Int J Epidemiol 2014;43:1089-96.

7. Laurens KR, Luo L, Matheson SL, et al. Common or distinct pathways to psychosis? A systematic review of evidence from prospective studies for developmental risk factors and antecedents of the schizophrenia spectrum disorders and affective psychoses. BMC Psychiatry 2015;15:1-20.

8. Laurens KR, Hobbs MJ, Sunderland M, et al. Psychotic-like experiences in a community sample of 8000 children aged 9 to 11 years: an item response theory analysis. Psychol Med 2012;42:1495-506

9. Drake C, Nickel C, Burduvali E, et al. The paediatric daytime sleepiness scale (PDSS): sleep habits and school outcomes in middle-school children. Sleep 2003;26:455-60.

10. Tim Gill. The Benefits of Children's Engagement with Nature: A Systematic Literature Review. Child Youth Environ 2014;24:10-34.

11. Brinkman S, Sayers M, Goldfeld S, et al. Population monitoring of language and cognitive development in Australia: the australian Early Development Index. Int J Speech Lang Pathol 2009;11:419-30.

12. Goodman R. The strengths and difficulties Questionnaire: a research note. J Child Psychol Psychiatry 1997;38:581-6.

13. Goodman R. Psychometric properties of the strengths and difficulties questionnaire. J Am Acad Child Adolesc Psychiatry 2001;40:1337-45.

14. Ainley J, Bourke S. Student views of primary schooling. Research Papers in Education 1992;7:107-28.

15. Hanson TL, Kim J. West REL, ed. Measuring resilience and youth development: the psychometric properties of the healthy kids survey. Issues \& answers. REL 2007-No. 34. San Francisco, CA: IES, 2007.

16. Schonert-Reichl KA, Guhn M, Gadermann AM, et al. Development and Validation of the Middle years Development Instrument (MDI): Assessing Children's Well-Being and Assets across Multiple Contexts. Soc Indic Res 2013;114:345-69.

17. Ellis LK, Rothbart MK. Revision of the early adolescent temperament questionnaire. biennial meeting of the Society for Research in Child Development. Minneapolis, MN: Poster reprint, 2001. http://www.bowdoin.edu/ sputnam/rothbart-temperamentquestionnaires/pdf/lesa-ellis-srcd-poster-reprint.pdf. (accessed 4 Aug 2016). 
18. Garton AF, Gringart E. The development of a scale to measure empathy in 8- and 9-year-old children. Aust J Educ \& Dev Psychol 2005;5:17-25.

19. Laurens KR, Hodgins S, Maughan B, et al. Community screening for psychotic-like experiences and other putative antecedents of schizophrenia in children aged 9-12 years. Schizophr Res 2007;90(13):130-46.

20. Barbaranelli C, Caprara GV, Rabasca A, et al. A questionnaire for measuring the big five in late childhood. Pers Individ Dif 2003;34:645-64.

21. Huebner ES. Preliminary development and validation of a multidimensional life satisfaction scale for children. Psychol Assess 1994;6:149-58.

22. Cheng JC-H, Monroe MC. Connection to Nature: children's Affective Attitude Toward Nature. Environ Behav 2012;44:31-49.

23. Mayer FS, Frantz CM. The connectedness to nature scale: a measure of individuals' feeling in community with nature. J Environ Psychol 2004;24:503-15.

24. Zumbo BD, Gadermann AM, Zeisser C. Ordinal versions of coefficients alpha and theta for Likert rating scales. J Modern Appl Stat Method 2007;6:21-9.

25. Kelleher I, Connor D, Clarke MC, et al. Prevalence of psychotic symptoms in childhood and adolescence: a systematic review and meta-analysis of population-based studies. Psychol Med 2012;42:1857-63.

26. Cohen J. A power primer. Psychol Bull 1992;112:155-9.
27. Mellor D. Normative data for the strengths and difficulties questionnaire in Australia. Aust Psychol 2005;40:215-22.

28. Fleming TM, Clark T, Denny S, et al. Stability and change in the mental health of New Zealand secondary school students 20072012: results from the national adolescent health surveys. Aust N Z J Psychiatry 2014;48:472-80.

29. Fink E, Patalay $\mathrm{P}$, Sharpe $\mathrm{H}$, et al. Mental Health Difficulties in early adolescence: a comparison of two Cross-Sectional studies in England from 2009 to 2014. J Adolesc Health 2015;56:502-7.

30. Kong C-K. Classroom learning experiences and students' perceptions of quality of school life. Learn Environ Res 2008;11:111-29.

31. Sun-Keung Pang N. Students' Perceptions of Quality of School Life in Hong Kong primary schools. J Educ Res 1999;14:1-23.

32. Muris $P$, Meesters $C$. Reactive and regulative temperament in Youths: psychometric evaluation of the early adolescent temperament Questionnaire-Revised. J Psychopathol Behav Assess 2009;31:7-19.

33. Gresham D, Gullone E. Emotion regulation strategy use in children and adolescents: the explanatory roles of personality and attachment. Pers Individ Dif 2012;52:616-21.

34. Goodman A, Goodman R. Population mean scores predict child mental disorder rates: validating SDQ prevalence estimators in Britain. J Child Psychol Psychiatry 2011;52:100-8.

35. van der Ende J, Verhulst FC, Tiemeier H. Agreement of informants on emotional and behavioral problems from childhood to adulthood. Psychol Assess 2012;24:293-300. 